\title{
Generalized combination equations for canopy evaporation under dry and wet conditions
}

\author{
J. P. Lhomme and C. Montes \\ IRD (UMR LISAH), 2 Place Viala, 34060 Montpellier, France
}

Correspondence to: J. P. Lhomme (jean-paul.lhomme@ird.fr)

Received: 7 August 2013 - Published in Hydrol. Earth Syst. Sci. Discuss.: 20 August 2013

Revised: 24 January 2014 - Accepted: 12 February 2014 - Published: 26 March 2014

\begin{abstract}
The formulation of canopy evaporation is investigated on the basis of the combination equation derived from the Penman equation. All the elementary resistances (surface and boundary layer) within the canopy are taken into account, and the exchange surfaces are assumed to be subject to the same vapour pressure deficit at canopy source height. This development leads to generalized combination equations: one for completely dry canopies and the other for partially wet canopies. These equations are rather complex because they involve the partitioning of available energy within the canopy and between the wet and dry surfaces. By making some assumptions and approximations, they can provide simpler equations similar to the common Penman-Monteith model. One of the basic assumptions of this down-grading process is to consider that the available energy intercepted by the different elements making up the canopy is uniformly distributed and proportional to their respective area. Despite the somewhat unrealistic character of this hypothesis, it allows one to retrieve the simple formulations commonly and successfully used up to now. Numerical simulations are carried out by means of a simple one-dimensional model of the vegetation-atmosphere interaction with two different leaf area profiles. In dry conditions and when the soil surface is moist (low surface resistance), there is a large discrepancy between the generalized formulation and its simpler Penman-Monteith form, but much less when the soil surface is dry. In partially wet conditions, the Penman-Monteithtype equation substantially underestimates the generalized formulation when leaves are evenly distributed, but provides better estimates when leaves are concentrated in the upper half of the canopy.
\end{abstract}

\section{Introduction}

The combination equation, which expresses the evaporation from natural surfaces, has certainly been one of the most successful breakthroughs in our understanding of evaporation. It is obtained by combining the energy balance equation with expressions of the convective fluxes of sensible and latent heat. The first equation of this type is the original Penman formula, initially derived to estimate the evaporation from a completely wet surface such as open water (Penman, 1948). It was extended by Monteith (1963) to describe the rate of evaporation from a dry surface characterized by a surface resistance $\left(r_{\mathrm{s}}\right)$ to vapour transfer added to the resistance of the air $\left(r_{\mathrm{a}}\right)$. The surface resistance is opposed to the transfer of water vapour between the level where evaporation takes place and the interface with the open air (source or sink of sensible heat). Provided both levels are at the same temperature, the Penman-Monteith equation is written as

$$
\lambda E=\frac{\Delta A+\rho c_{\mathrm{p}} D_{\mathrm{a}} / r_{\mathrm{a}}}{\Delta+\gamma\left(1+r_{\mathrm{s}} / r_{\mathrm{a}}\right)},
$$

where $A$ is the available energy of the surface and $D_{\mathrm{a}}$ the vapour pressure deficit of the air. A familiar example is a thin dry layer covering a wet soil or a single leaf with its epidermis exchanging sensible heat and its stomatal cavities acting as a source of water vapour. Equation (1) simplifies into Penman equation when $r_{\mathrm{s}}=0$.

Monteith $(1963,1965)$ extended Eq. (1) to a stand of vegetation assuming the canopy to exchange sensible and latent heat with the atmosphere from a theoretical surface located at the same level as the effective sink of momentum: $z_{\mathrm{m}}=d+z_{0}\left(d\right.$ : displacement height; $z_{0}$ : roughness length). The aerodynamic resistance $r_{\mathrm{a}}$ (assumed to be the same for sensible and latent heat) is calculated between this level and 
the reference height, where $D_{\mathrm{a}}$ is measured. The original idea of Monteith to place the source surface at level $z_{\mathrm{m}}$ is a priori questionable, because no real theoretical basis supports it. Thom (1972) showed that the transfer of heat and mass encounters greater aerodynamic resistance than momentum; therefore, the effective source of sensible and latent heat should be located at a lower level: $d+z_{0 h}$ with $z_{0 h}<z_{0}$ (e.g. Garrat and Hicks, 1973). The excess resistance $\left(r_{\mathrm{a}, \mathrm{ex}}\right)$, associated with the boundary-layer resistances for the transfer of water vapour and sensible heat, is commonly expressed as $B^{-1} / u *$, where $B^{-1}$ is a dimensionless bulk parameter and $u *$ is the friction velocity: $B^{-1}$ is linked to $z_{0 h}$ by $B^{-1}=$ $\ln \left(\mathrm{z}_{0} / z_{0 h}\right) / k$. According to Monteith (1965), the surface resistance $\left(r_{\mathrm{s}}\right)$ is expected to be a plant factor depending on the stomatal resistance of individual leaves and on foliage area (soil evaporation being neglected). It is interpreted as the effective stomatal resistance of all the leaves acting as resistances in parallel (Shuttleworth, 1976b):

$\frac{1}{r_{\mathrm{s}}}=\sum_{i} \frac{1}{r_{\mathrm{s}, i}}$

$r_{\mathrm{s}, i}$ being the stomatal resistance of an individual leaf $i$. The Penman-Monteith equation is often called "big-leaf model" because the whole canopy is assimilated to a big leaf located at level $d+z_{0}$ and with stomatal resistance $r_{\mathrm{s}}$. The transfer processes through the air surrounding the leaves, supposedly negligible, are not taken into account or indirectly through the excess resistance. The lack of theoretical foundation of Eq. (1) applied to a canopy of leaves was apparent in a controversy which occurred in the 1970s about the formulation of evaporation from partially wet canopies (Shuttleworth, 1976a, 1977; Monteith, 1977). The Penman-Monteith equation was considered not to be able to represent the transition between dry and wet canopies, because the definition of canopy resistance according to Penman-Monteith (Eq. 2) implies that, if only a small part of the canopy is wet $\left(r_{\mathrm{s}, i}=0\right)$, the canopy resistance $r_{\mathrm{s}}$ should be equal to zero, which is unrealistic.

In this context, the main objectives of the paper are to investigate, under dry and wet conditions, the theoretical foundations of the combination equation applied to a canopy of leaves and concurrently to examine the different ways of aggregating the in-canopy resistances (surface and air) in a general single-source formulation of canopy evaporation. The basic principles used in the study are similar to those established by Shuttleworth (1978) in his simplified description of the vegetation-atmosphere interaction: the whole canopy (soil surface included) is assumed to be subject to the same vapour pressure deficit $D_{\mathrm{m}}$ at the mean source height $z_{\mathrm{m}}\left(d+z_{0}\right)$, as in the original Penman-Monteith model and in two-source models (Shuttleworth and Wallace, 1985). Our investigation follows up previous works made on the formulation of evaporation from heterogeneous and sparse canopies (Lhomme et al., 2012, 2013). We show that the generalized formulation derived by Lhomme et al. (2013, Eq. 12)

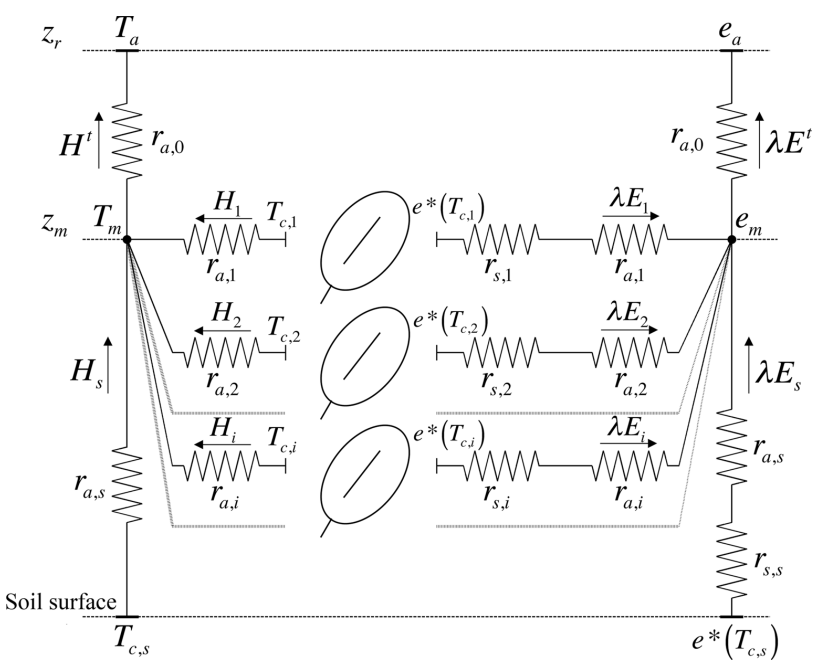

Fig. 1. Resistance network and potentials for a canopy represented by its elementary exchange surfaces (see list of symbols). All the component fluxes (sensible heat $H_{i}$ and latent heat $\lambda E_{i}$ ) converge at canopy source height $\left(z_{\mathrm{m}}\right) . T_{\mathrm{c}, \mathrm{s}}$ is soil surface temperature.

for multi-component canopies can be applied to a simple canopy, where the individual leaves and soil surface constitute the different components, and can be rewritten in a form similar to a combination equation. Different levels of approximation are identified to transform the general formulation of evaporation into the common Penman-Monteith equation. In this way, a bridge is established between a complex multisource representation and the common practice based on the Penman-Monteith model with two bulk resistances (air and surface). The question of the "excess" resistance, linked to the exact location of the canopy source height, is also indirectly dealt with. Finally, the errors made when applying simple equations of the Penman-Monteith type instead of the more general ones are numerically assessed.

\section{Evaporation from a dry canopy}

\subsection{General formulation}

The canopy exchanges sensible and latent heat with the atmosphere through its leaf area and its soil surface. The modelling framework describing this interaction is similar to the one used by Lhomme et al. (2013) to derive the formulation of evaporation from a canopy made of $n$ different components; however, the individual components or elements are represented here by the different leaves of the canopy and the soil surface, as shown in Fig. 1. The elementary evaporation $\left(\lambda E_{i}\right)$ per unit area of exchange surface (each side of a leaf being considered separately) is calculated from an equation of the Penman-Monteith type. It involves the saturation deficit of the air at canopy source height $\left(D_{\mathrm{m}}\right)$ and the available energy $\left(A_{i}\right)$ for element $i$ within the canopy (Lhomme 
et al., 2012):

$\lambda E_{i}=\frac{\Delta A_{i}+\rho c_{\mathrm{p}} D_{\mathrm{m}} / r_{\mathrm{a}, i}}{\Delta+\gamma\left(1+r_{\mathrm{s}, i} / r_{\mathrm{a}, i}\right)}$.

In Eq. (3), for the canopy leaves, $A_{i}$ is the net radiation per unit area of leaf, $r_{\mathrm{s}, i}$ the leaf stomatal resistance (one side) per unit area of leaf and $r_{\mathrm{a}, i}$ the corresponding leaf boundarylayer resistance for sensible and latent heat. For the soil surface symbolized by subscript $i=\mathrm{s}, A_{\mathrm{s}}$ is the net radiation minus the soil heat flux per unit area of soil, $r_{\mathrm{s}, \mathrm{s}}$ being the soil surface resistance to evaporation and $r_{\mathrm{a}, \mathrm{s}}$ the air resistance between the soil surface and the canopy source height $\left(z_{\mathrm{m}}\right)$, defined by integrating the reciprocal of the appropriate eddy diffusivity (Choudhury and Monteith, 1988). Canopy leaf area index (LAI) being noted $L_{\mathrm{t}}$, the total exchange surface area per unit area of soil is $S_{\mathrm{t}}=2 L_{\mathrm{t}}+1$ and total evaporation is obtained by summing the contributions of each individual exchange surface (soil and leaves):

$\lambda E^{\mathrm{t}}=\sum_{i \in S_{\mathrm{t}}} \lambda E_{i}$

The vapour pressure deficit $\left(D_{\mathrm{m}}\right)$ in Eq. (3) is calculated from the vapour pressure deficit at reference height $\left(D_{\mathrm{a}}\right)$ (Shuttleworth and Wallace, 1985; Lhomme et al., 2013):

$D_{\mathrm{m}}=D_{\mathrm{a}}+\left[\Delta A-(\Delta+\gamma) \lambda E^{\mathrm{t}}\right] r_{\mathrm{a}, 0} /\left(\rho c_{\mathrm{p}}\right)$,

where $A$ is the available energy of the whole canopy and $r_{\mathrm{a}, 0}$ the aerodynamic resistance between the mean source height $\left(z_{\mathrm{m}}\right)$ and the reference height $\left(z_{\mathrm{r}}\right)$. Defining

$R_{i}=r_{\mathrm{s}, i}+\left(1+\frac{\Delta}{\gamma}\right) r_{\mathrm{a}, i}$,

and introducing Eq. (5) into Eq. (3) and Eq. (3) into Eq. (4) leads to

$\lambda E^{\mathrm{t}}=\frac{\Delta\left[A+\left(R_{\mathrm{c}} / r_{\mathrm{a}, 0}\right) \sum_{i \in S_{\mathrm{t}}}\left(A_{i} r_{\mathrm{a}, i} / R_{i}\right)\right]+\rho c_{\mathrm{p}} D_{\mathrm{a}} / r_{\mathrm{a}, 0}}{\Delta+\gamma\left(1+R_{\mathrm{c}} / r_{\mathrm{a}, 0}\right)}$,

where $R_{\mathrm{c}}$ is expressed as

$\frac{1}{R_{\mathrm{c}}}=\sum_{i \in S_{\mathrm{t}}} \frac{1}{R_{i}}$.

Equations (7) and (8) represent a kind of generalized combination equation, where all the within-canopy resistances (air and surface) are taken into account. $R_{\mathrm{c}}$ defines a bulk canopy resistance which includes the surface resistances (leaves and soil) and the air resistances within the canopy. The temperature of each exchange surface can be determined from the above equations, as detailed in Appendix B.

If the boundary-layer resistances $\left(r_{\mathrm{a}, i}\right)$ within the canopy are neglected, assuming they are small compared to their stomatal counterpart (which is the assumption made in the Penman-Monteith equation), Eqs. (7) and (8) can be easily simplified. Excluding the soil component and putting $r_{\mathrm{a}, i}=0$, the summation in the right-hand term of Eq. (8) defines the canopy stomatal resistance in the sense of Monteith denoted by $r_{\mathrm{s}, \mathrm{c}}$ :

$\frac{1}{R_{\mathrm{c}}}=\frac{1}{r_{\mathrm{s}, \mathrm{c}}}=\sum_{i \in 2 L_{\mathrm{t}}} 1 / r_{\mathrm{s}, i} \approx \frac{2 L_{\mathrm{t}}}{\left\langle r_{\mathrm{s}, 1^{\prime}}\right.}$,

where $\left\langle r_{\mathrm{s}, 1}\right\rangle$ is the harmonic mean of leaf stomatal resistances (per unit one-sided leaf area). The different leaves of the canopy acting as parallel resistors for the transfer of sensible heat and water vapour, harmonic means should be chosen when combining the elementary resistances (whereas arithmetic means would be used if conductances were considered). For a hypostomatous canopy, $2 L_{\mathrm{t}}$ should be replaced by $L_{\mathrm{t}}$. Hence Eq. (7) becomes

$\lambda E^{\mathrm{t}}=\frac{\Delta A+\rho c_{\mathrm{p}} D_{\mathrm{a}} / r_{\mathrm{a}, 0}}{\Delta+\gamma\left(1+r_{\mathrm{s}, \mathrm{c}} / r_{\mathrm{a}, 0}\right)}$.

Equation (10) is the well-known Penman-Monteith equation, which appears now as a particular case of a more general equation (Eq. 7), when all the air resistances within the canopy are set to zero and soil surface is neglected.

The case of a completely wet canopy can also be inferred from Eq. (7). When all the exchange surfaces (leaves and soil surface) are wet, the surface resistances $\left(r_{\mathrm{s}, i}\right)$ are nil and $R_{i}$ $=(1+\Delta / \gamma) r_{\mathrm{a}, i}$. Noting that $\sum_{i \in S_{\mathrm{t}}} A_{i}=A$ and after some manipulations, Eq. (7) transforms into a Penman-type equation:

$\lambda E^{\mathrm{t}}=\frac{\Delta A+\rho c_{\mathrm{p}} D_{\mathrm{a}} /\left(r_{\mathrm{a}, 0}+r_{\mathrm{a}, \mathrm{c}}\right)}{\Delta+\gamma}$,

where

$\frac{1}{r_{\mathrm{a}, \mathrm{c}}}=\sum_{i \in S_{\mathrm{t}}} \frac{1}{r_{\mathrm{a}, i}} \approx \frac{2 L_{\mathrm{t}}}{\left\langle r_{\mathrm{a}, 1}\right\rangle}+\frac{1}{r_{\mathrm{a}, \mathrm{s}}}$,

$\left\langle r_{\mathrm{a}, 1}\right\rangle$ being the harmonic mean of leaf boundary-layer resistances and $r_{\mathrm{a}, \mathrm{s}}$ the air resistance between the soil surface and the canopy source height. There is no surface resistance in the denominator of Eq. (11), as in the original Penman equation, but an additional air resistance $\left(r_{\mathrm{a}, \mathrm{c}}\right)$ is added to the common aerodynamic resistance above the canopy $\left(r_{\mathrm{a}, 0}\right)$. This additional resistance is the parallel sum of individual air resistances and encapsulates the bulk canopy resistance to heat and water vapour transfer from the wet exchange surfaces (leaves and soil) to the canopy source height.

\subsection{Penman-Monteith-type formulation}

The general combination equation derived above (Eq. 7) does not follow the exact form of the Penman-Monteith equation since an additional term mixing resistances with available energy partitioning is added to the total available energy $(A)$. This section investigates under which conditions 
and approximations this general formula of canopy evaporation can be put in the simplified form of a Penman-Monteith equation, without neglecting the air resistances within the canopy. The approximations made below are essentially dictated by the result we aim at: i.e. the common form of the Penman-Monteith equation with bulk resistances expressed in a simple way.

The variable $A_{i}$ giving the partition of available energy within the canopy is assumed to be in the form $A_{i}=A \Phi(i)$, where $A$ is the total available energy for the whole canopy and $\Phi(i)$ is a function resulting from the radiative transfers within the canopy and depending on canopy structure and leaf area distribution. Beer's law, which is commonly used to express the attenuation of net radiation within the canopy, is typically a function of this kind. This assumption on the repartition of available energy is certainly a crude approximation. It is required, however, to mathematically derive a Penman-Monteith-type equation from the generalized form of Eq. (7), which means that the former implicitly includes this assumption. Consequently, after some manipulations, it can be shown that canopy evaporation (Eq. 7) can be written as

$\lambda E^{\mathrm{t}}=\frac{\Delta A+\rho c_{\mathrm{p}} D_{\mathrm{a}} /\left(r_{\mathrm{a}, 0}+r_{\mathrm{a}, \mathrm{c}}\right)}{\Delta+\gamma\left[1+r_{\mathrm{s}, \mathrm{c}} /\left(r_{\mathrm{a}, 0}+r_{\mathrm{a}, \mathrm{c}}\right)\right]}$,

where the bulk resistances $r_{\mathrm{a}, \mathrm{c}}$ and $r_{\mathrm{s}, \mathrm{c}}$ are defined as

$r_{a, c}=R_{c} \sum_{i \in S_{\mathrm{t}}} \Phi_{i} \frac{r_{a, i}}{R_{i}}$

$r_{\mathrm{s}, \mathrm{c}}=R_{\mathrm{c}}\left[1-\left(1+\frac{\Delta}{\gamma}\right) \sum_{i \in S_{\mathrm{t}}} \Phi_{i} \frac{r_{\mathrm{a}, i}}{R_{i}}\right]$.

The resistances defined above involve air and surface resistances and the distribution function of available energy within the canopy. In order to get simpler formulations, some approximations are made substituting average values to summations. Introducing the harmonic mean of surface resistances per unit area of exchange surface $\left\langle r_{\mathrm{s}, i}\right\rangle$ and the corresponding harmonic mean of leaf boundary-layer resistances noted $\left\langle r_{\mathrm{a}, i}\right\rangle$, Eq. (8) can be written as

$$
\frac{1}{R_{\mathrm{c}}} \approx \frac{S_{\mathrm{t}}}{\left\langle R_{i}\right\rangle} .
$$

Summation in Eqs. (14) and (15) can be approximated using means denoted by angle brackets:

$\sum_{i \in S_{\mathrm{t}}} \Phi_{i} \frac{r_{\mathrm{a}, i}}{R_{i}} \approx\left\langle\frac{\Phi_{i} r_{\mathrm{a}, i}}{R_{i}}\right\rangle S_{\mathrm{t}} \approx \frac{S_{\mathrm{t}}}{\left\langle R_{i}\right\rangle}\left\langle\Phi_{i} r_{\mathrm{a}, i}\right\rangle$.

Substituting Eqs. (16) and (17) into Eqs. (14) and (15) leads to the following approximate expressions for bulk canopy resistances:

$r_{\mathrm{a}, \mathrm{c}} \approx\left\langle\Phi_{i} r_{\mathrm{a}, i}\right\rangle$ $r_{\mathrm{s}, \mathrm{c}} \approx \frac{\left\langle R_{i}\right\rangle}{S_{\mathrm{t}}}-\left(1+\frac{\Delta}{\gamma}\right)\left\langle\Phi_{i} r_{\mathrm{a}, i}\right\rangle$.

These expressions still depend upon available energy partitioning, but it is interesting to note that if available energy is equally distributed within the canopy (soil included), i.e. $\Phi_{i}=1 / S_{\mathrm{t}}$, the bulk air and surface resistances reduce to simple expressions independent of available energy. Although this assumption is not really realistic and constitutes a priori a strong approximation, it has been used by Shuttleworth (1978) in his "simplified general model". Using this assumption and separating the soil and leaves components $\left(S_{\mathrm{t}}=2 L_{\mathrm{t}}+1\right)$, the bulk canopy resistances can be rewritten in a way similar to Eqs. (12) and (9):

$$
\begin{aligned}
& \frac{1}{r_{\mathrm{a}, \mathrm{c}}} \approx \frac{S_{\mathrm{t}}}{\left\langle r_{\mathrm{a}, i}\right\rangle}=\frac{2 L_{\mathrm{t}}}{\left\langle r_{\mathrm{a}, 1}\right\rangle}+\frac{1}{r_{\mathrm{a}, \mathrm{s}}}, \\
& \frac{1}{r_{\mathrm{s}, \mathrm{c}}} \approx \frac{S_{\mathrm{t}}}{\left\langle R_{i}\right\rangle-\left(1+\frac{\Delta}{\gamma}\right)\left\langle r_{\mathrm{a}, i}\right\rangle}=\frac{S_{\mathrm{t}}}{\left\langle r_{\mathrm{s}, i}\right\rangle}=\frac{2 L_{\mathrm{t}}}{\left\langle r_{\mathrm{s}, 1}\right\rangle}+\frac{1}{r_{\mathrm{s}, \mathrm{s}}},
\end{aligned}
$$

where $\left\langle r_{\mathrm{a}, 1}\right\rangle$ and $\left\langle r_{\mathrm{s}, 1}\right\rangle$ are the harmonic means of leaf boundary-layer resistances and stomatal resistances respectively. If the canopy is hypostomatous and if the average stomatal resistance $\left\langle r_{\mathrm{s}, 1}\right\rangle$ applies to the lower side of the leaves, $2 L_{\mathrm{t}}$ should be replaced by $L_{\mathrm{t}}$ in Eq. (21). Equation (13) appears now as a typical Penman-Monteith equation with its bulk resistances defined in the conventional way. The canopy surface resistance $\left(r_{\mathrm{s}, \mathrm{c}}\right)$ accounts for all surface resistances, including leaves and soil. The "extra" resistance $\left(r_{\mathrm{a}, \mathrm{c}}\right)$, added to the common aerodynamic resistance above the canopy $\left(r_{\mathrm{a}, 0}\right)$, accounts for the air resistances opposed to heat and water vapour transfer within the canopy and can be perceived as similar to the excess resistance $\left(B^{-1} / u *\right)$ introduced by Thom (1972) in the formulation of canopy evaporation.

\section{Evaporation from a partially wet canopy}

The partially wet canopy is taken here in the sense of "double canopy limit” described by Shuttleworth (1976b, 1978), all the individual elements being considered either totally dry or totally wet. It is opposed to the "single canopy limit", where the distribution of surface water resembles that of stomata, as when droplets of fog and mist impact the leaves. The "double canopy" is the most realistic case applicable to canopies which are drying out or in the process of wetting up by rainfall.

\subsection{General formulation}

The whole canopy is divided into two parts assumed to be independent: one is dry (with exchange surface $S_{\mathrm{d}}$ ) and the 
other wet (with exchange surface $S_{\mathrm{w}}$ ) and $S_{\mathrm{t}}=S_{\mathrm{d}}+S_{\mathrm{w}}$. The assumption of independence is certainly questionable, but, as expressed by Shuttleworth (1978, p. 8): "such an assumption is certainly essential if theoretical progress is to be made in this field". Consequently, Eq. (4) can be rewritten in the following way:

$\lambda E^{\mathrm{t}}=\lambda E^{\mathrm{d}}+\lambda E^{\mathrm{w}}=\sum_{i \in S_{\mathrm{d}}} \lambda E_{i}+\sum_{i \in S_{\mathrm{w}}} \lambda E_{i}$.

After substituting the expression of $D_{\mathrm{m}}$ (Eq. 5) into Eq. (3), elementary evaporation can be rewritten as

$\lambda E_{i}=\left[\frac{\Delta}{\gamma}\left(r_{\mathrm{a}, i} A_{i}+r_{\mathrm{a}, 0} A\right)+\left(\frac{\rho c_{\mathrm{p}}}{\gamma}\right) D_{\mathrm{a}}-\left(1+\frac{\Delta}{\gamma}\right) r_{\mathrm{a}, 0} \lambda E^{\mathrm{t}}\right] / R_{i}$,

where $R_{i}$ is given by Eq. (6). Bulk canopy resistances for the dry and wet parts of the canopy will be respectively defined as

$\frac{1}{R_{\mathrm{c}, \mathrm{d}}}=\sum_{i \in S_{\mathrm{d}}} \frac{1}{R_{i}}$ and $\frac{1}{R_{\mathrm{c}, \mathrm{w}}}=\sum_{i \in S_{\mathrm{w}}} \frac{1}{r_{\mathrm{a}, i}}$.

With these definitions, the evaporation from the dry part of the canopy can be written as

$$
\begin{array}{r}
\lambda E^{\mathrm{d}}=\frac{\Delta}{\gamma}\left(\frac{r_{\mathrm{a}, 0}}{R_{\mathrm{c}, \mathrm{d}}} A+\sum_{i \in S_{\mathrm{d}}} \frac{r_{\mathrm{a}, i} A_{i}}{R_{i}}\right) \\
+\frac{\rho c_{\mathrm{p}}}{\gamma} \cdot \frac{D_{\mathrm{a}}}{R_{\mathrm{c}, \mathrm{d}}}-\left(1+\frac{\Delta}{\gamma}\right) \frac{r_{\mathrm{a}, 0}}{R_{\mathrm{c}, \mathrm{d}}} \lambda E^{\mathrm{t}},
\end{array}
$$

and the contribution of the wet part is

$\lambda E^{\mathrm{w}}=\frac{\Delta}{\Delta+\gamma}\left(\frac{r_{\mathrm{a}, 0}}{R_{\mathrm{c}, \mathrm{w}}} A+\sum_{i \in S_{\mathrm{w}}} A_{i}\right)+\frac{\rho c_{\mathrm{p}}}{\Delta+\gamma} \cdot \frac{D_{\mathrm{a}}}{R_{\mathrm{c}, \mathrm{w}}}-\frac{r_{\mathrm{a}, 0}}{R_{\mathrm{c}, \mathrm{w}}} \lambda E^{\mathrm{t}}$.

After some rearrangement, putting $A_{\mathrm{w}}=\sum_{i \in S_{\mathrm{w}}} A_{i}$ and defining a bulk canopy resistance for a partially wet canopy as

$$
\frac{1}{R_{\mathrm{c}, \mathrm{pw}}}=\frac{1}{R_{\mathrm{c}, \mathrm{d}}}+\frac{\gamma}{\Delta+\gamma} \frac{1}{R_{\mathrm{c}, \mathrm{w}}}
$$

Eq. (22) becomes

$$
\lambda E^{\mathrm{t}}=\frac{\Delta\left\{A+\frac{R_{\mathrm{c}, \mathrm{pw}}}{r_{\mathrm{a}, 0}}\left[\left(\frac{\gamma}{\Delta+\gamma}\right) A_{\mathrm{w}}+\sum_{i \in S_{\mathrm{d}}} \frac{r_{\mathrm{a}, i} A_{i}}{R_{i}}\right]\right\}+\rho c_{\mathrm{p}} \frac{D_{\mathrm{a}}}{r_{\mathrm{a}, 0}}}{\Delta+\gamma\left(1+R_{\mathrm{c}, \mathrm{pw}} / r_{\mathrm{a}, 0}\right)} .
$$

The contribution of each part of the canopy (wet and dry) to total evaporation is obtained by replacing $\lambda E^{\mathrm{t}}$ by its expression in Eqs. (25) and (26). As could be expected, the limit of Eq. (28) when the canopy becomes completely dry is Eq. (7), and it is Eq. (11) when it becomes entirely wet. Consequently, Eq. (28) constitutes a kind of generalized combination equation applicable in all conditions (dry, wet or partially wet canopy). It is also a different and simpler writing of the single-source limit of the general model developed by
Shuttleworth (1976b, 1978). It is worthwhile noting that neglecting the air resistances within the canopy (i.e. $r_{\mathrm{a}, i}=0$ ) would lead to an inconsistency, as is the case for the PenmanMonteith equation applied in partially wet conditions. The bulk resistance $R_{\mathrm{c}, \mathrm{pw}}$ would become zero and Eq. (28) would turn into a simple Penman equation, which is not realistic.

\subsection{Penman-Monteith-type formulation}

This section examines under which conditions and approximations the general evaporation formula for partially wet canopies (Eq. 28) can be put in a form similar to the PenmanMonteith equation with simply defined resistances. Considering an amphistomatous canopy, the same assumptions as those made by Shuttleworth (1978) to derive the "Double Canopy Limit of the Simplified General model" are used here: (i) soil surface is neglected; (ii) a proportion $W$ of the canopy is taken as wet, which means that $S_{\mathrm{w}}=\mathrm{WS}_{\mathrm{t}}$ and $S_{\mathrm{d}}$ $=(1-W) S_{\mathrm{t}}$ with $S_{\mathrm{t}}=2 L_{\mathrm{t}}$; (iii) as discussed above, available energy is assumed to be equally distributed amongst the exchange surfaces, which implies that the available energy of each part (wet and dry) is proportional to its area: $A_{\mathrm{w}}=$ AW and $A_{\mathrm{d}}=A(1-W)$. Substituting average values to summations, Eq. (24) can be approximated by

$\frac{1}{R_{\mathrm{c}, \mathrm{w}}} \approx \frac{2 W L_{\mathrm{t}}}{\left\langle r_{\mathrm{a}, 1, \mathrm{w}}\right\rangle}$

where $\left\langle r_{\mathrm{a}, 1, \mathrm{w}}\right\rangle$ represents the average value of leaf boundarylayer resistances for the wet part of the canopy, and

$\frac{1}{R_{\mathrm{c}, \mathrm{d}}} \approx \frac{2(1-W) L_{\mathrm{t}}}{\left\langle r_{\mathrm{s}, 1, \mathrm{~d}}\right\rangle+\left(1+\frac{\Delta}{\gamma}\right)\left\langle r_{\mathrm{a}, 1, \mathrm{~d}}\right\rangle}$,

where $\left\langle r_{\mathrm{a}, \mathrm{l}, \mathrm{d}}\right\rangle$ and $\left\langle r_{\mathrm{s}, \mathrm{l}, \mathrm{d}}\right\rangle$ represent the average values of leaf resistances (air and surface) for the dry part of the canopy. Two bulk air resistances $\left(r_{\mathrm{a}, \mathrm{c}, \mathrm{w}}\right.$ and $\left.r_{\mathrm{a}, \mathrm{c}, \mathrm{d}}\right)$, respectively for the wet and dry parts of the canopy, and a bulk surface resistance $\left(r_{\mathrm{s}, \mathrm{c}, \mathrm{d}}\right)$ for the dry part, are defined in the following way:

$\frac{1}{r_{\mathrm{a}, \mathrm{c}, \mathrm{w}}}=\frac{2 W L_{\mathrm{t}}}{\left\langle r_{\mathrm{a}, 1, \mathrm{w}}\right\rangle}$,

$\frac{1}{r_{\mathrm{a}, \mathrm{c}, \mathrm{d}}}=\frac{2(1-W) L_{\mathrm{t}}}{\left\langle r_{\mathrm{a}, \mathrm{l}, \mathrm{d}}\right\rangle}$,

$\frac{1}{r_{\mathrm{s}, \mathrm{c}, \mathrm{d}}}=\frac{2(1-W) L_{\mathrm{t}}}{\left\langle r_{\mathrm{s}, \mathrm{l}, \mathrm{d}}\right\rangle}$.

Consequently, Eq. (27) can be rewritten as a function of the bulk resistances defined above:

$\frac{1}{R_{\mathrm{c}, \mathrm{pw}}}=\frac{r_{\mathrm{s}, \mathrm{c}, \mathrm{d}}+\left(1+\frac{\Delta}{\gamma}\right)\left(r_{\mathrm{a}, \mathrm{c}, \mathrm{w}}+r_{\mathrm{a}, \mathrm{c}, \mathrm{d}}\right)}{\left(1+\frac{\Delta}{\gamma}\right) r_{\mathrm{a}, \mathrm{c}, \mathrm{w}}\left[r_{\mathrm{s}, \mathrm{c}, \mathrm{d}}+\left(1+\frac{\Delta}{\gamma}\right) r_{\mathrm{a}, \mathrm{c}, \mathrm{d}}\right]}$. 
The assumption on the equal distribution of available energy $\left(A_{i}=A /\left(2 L_{\mathrm{t}}\right)\right)$ leads to

$$
\begin{gathered}
\sum_{i \in S_{\mathrm{d}}} \frac{r_{\mathrm{a}, i} A_{i}}{R_{i}} \approx \frac{A}{2 L_{\mathrm{t}}} \cdot \frac{\left\langle r_{\mathrm{a}, \mathrm{l}, \mathrm{d}}\right\rangle}{\left\langle r_{\mathrm{s}, \mathrm{l}, \mathrm{d}}\right\rangle+\left(1+\frac{\Delta}{\gamma}\right)\left\langle r_{\mathrm{a}, \mathrm{l}, \mathrm{d}}\right\rangle} \cdot 2(1-W) L_{\mathrm{t}} \\
=\frac{A(1-W) r_{\mathrm{a}, \mathrm{c}, \mathrm{d}}}{r_{\mathrm{s}, \mathrm{c}, \mathrm{d}}+\left(1+\frac{\Delta}{\gamma}\right) r_{\mathrm{a}, \mathrm{c}, \mathrm{d}}} .
\end{gathered}
$$

The generalized equation in partially wet conditions (Eq. 28) can be rewritten in a form similar to the Penman-Monteith equation as

$\lambda E^{\mathrm{t}}=\frac{\Delta A+\rho c_{\mathrm{p}} D_{\mathrm{a}} /\left(r_{\mathrm{a}, 0}+r_{\mathrm{a}, \mathrm{pw}}\right)}{\Delta+\gamma\left[1+\frac{r_{\mathrm{s}, \mathrm{pw}}}{r_{\mathrm{a}, 0}+r_{\mathrm{a}, \mathrm{pw}}}\right]}$,

where the parameters $r_{\mathrm{a}, \mathrm{pw}}$ and $r_{\mathrm{s}, \mathrm{pw}}$ have the dimension of resistance and are defined as

$r_{\mathrm{a}, \mathrm{pw}}=\frac{r_{\mathrm{a}, \mathrm{c}, \mathrm{w}}\left[W r_{\mathrm{s}, \mathrm{c}, \mathrm{d}}+\left(1+\frac{\Delta}{\gamma}\right) r_{\mathrm{a}, \mathrm{c}, \mathrm{d}}\right]}{r_{\mathrm{s}, \mathrm{c}, \mathrm{d}}+\left(1+\frac{\Delta}{\gamma}\right)\left(r_{\mathrm{a}, \mathrm{c}, \mathrm{d}}+r_{\mathrm{a}, \mathrm{c}, \mathrm{w}}\right)}$,

$r_{\mathrm{s}, \mathrm{pw}}=\frac{\left(1+\frac{\Delta}{\gamma}\right)(1-W) r_{\mathrm{a}, \mathrm{c}, \mathrm{w}} r_{\mathrm{s}, \mathrm{c}, \mathrm{d}}}{r_{\mathrm{s}, \mathrm{c}, \mathrm{d}}+\left(1+\frac{\Delta}{\gamma}\right)\left(r_{\mathrm{a}, \mathrm{c}, \mathrm{d}}+r_{\mathrm{a}, \mathrm{c}, \mathrm{w}}\right)}$.

Equation (36), however, has not the strict form of the Penman-Monteith equation, where an air resistance divides $D_{\text {a }}$ in the numerator and where the ratio between a surface resistance and an air resistance appears in the denominator, because $r_{\mathrm{a}, \mathrm{pw}}$ includes a surface resistance $\left(r_{\mathrm{s}, \mathrm{c}, \mathrm{d}}\right)$ and consequently is not a "pure" air resistance. Additional assumptions should be made if we want to derive a strict Penman-Monteith equation. First, the mean (harmonic) leaf boundary-layer resistance should be assumed to be the same for the dry and wet parts of the canopy and equal to that of the whole canopy, which means that the bulk resistances can be rewritten as $r_{\mathrm{a}, \mathrm{c}, \mathrm{w}}=r_{\mathrm{a}, \mathrm{c}} / W$ and $r_{\mathrm{a}, \mathrm{c}, \mathrm{d}}=r_{\mathrm{a}, \mathrm{c}} /(1-W)$ with $r_{\mathrm{a}, \mathrm{c}}$ the bulk air resistance of the whole canopy (defined as in Eq. (20) without the soil component). Second, the mean (harmonic) leaf surface resistance for the dry part of the canopy should be assumed to be equal to that of the whole canopy, which leads to $r_{\mathrm{s}, \mathrm{c}, \mathrm{d}}=r_{\mathrm{s}, \mathrm{c}} /(1-W)$ with $r_{\mathrm{s}, \mathrm{c}}$ the bulk surface resistance of the whole canopy (defined as in Eq. (21) without the soil component). Under these conditions, $r_{\mathrm{a}, \mathrm{pw}}$ simplifies into $r_{\mathrm{a}, \mathrm{c}}$, and $r_{\mathrm{s}, \mathrm{pw}}$ can be rewritten in a simpler way as

$r_{\mathrm{s}, \mathrm{pw}}=\frac{(1-W) r_{\mathrm{a}, \mathrm{c}} r_{\mathrm{s}, \mathrm{c}}}{r_{\mathrm{a}, \mathrm{c}}+\frac{\gamma}{\Delta+\gamma} W r_{\mathrm{s}, \mathrm{c}}}$.

Equation (36) becomes

$\lambda E^{\mathrm{t}}=\frac{\Delta A+\rho c_{\mathrm{p}} D_{\mathrm{a}} /\left(r_{\mathrm{a}, 0}+r_{\mathrm{a}, \mathrm{c}}\right)}{\Delta+\gamma\left[1+\frac{r_{\mathrm{s}, \mathrm{pw}}}{r_{\mathrm{a}, 0}+r_{\mathrm{a}, \mathrm{c}}}\right]}$.
Equation (40) has now the typical form of a PenmanMonteith equation, because $r_{\mathrm{a}, 0}+r_{\mathrm{a}, \mathrm{c}}$ is a "pure" air resistance. Equation (39), which represents the canopy surface resistance in partially wet conditions, was initially derived by Shuttleworth (1978, Eq. 32; 2007, Eq. 16) using a different procedure, but with similar assumptions (those specified above and "intrinsic" resistances being disregarded). When $W=1$ (totally wet canopy), $r_{\mathrm{s}, \mathrm{pw}}=0$ and Eq. (40) reduces to a Penman-type equation (Eq. 11), as could be expected. When $W=0$ (totally dry canopy), $r_{\mathrm{s}, \mathrm{pw}}=r_{\mathrm{s}, \mathrm{c}}$ and Eq. (40) reduces to the Penman-Monteith equation defined by Eq. (13).

\section{Numerical simulations}

In order to illustrate the different equations developed above and to assess the errors made when using simplified equations instead of the more comprehensive ones, numerical simulations were undertaken. Table 1 summarizes the different formulations or methods and specifies the corresponding equations and their notations. The simulations are based upon a simple one-dimensional model describing the vegetation-atmosphere interaction.

\subsection{The simulation process}

In the modelling approach, the crop canopy is considered as horizontally homogeneous with a mean height $z_{\mathrm{h}}$. It is divided into several parallel layers (width $\Delta z_{i}$ ) counted from 1 to $n$ from the top of the canopy to the soil surface. The different components or unit exchange surfaces $(i)$ of the system are represented here by the different layers of vegetation making up the canopy plus the soil surface. This modelling approach is different from the traditional multi-layer approach (Waggoner and Reifsnyder, 1968) in the sense that each layer is subject to the same saturation deficit $\left(D_{\mathrm{m}}\right)$ without the inclusion of aerodynamic resistances in relation to the vertical transfer of sensible heat and water vapour. The parameterizations used for the microclimatic profiles, leaf area distribution, air and surface resistances are given in Appendix C. The available energy for each layer (see Eq. C2) is expressed as

$A_{i}=c R_{\mathrm{n}, \mathrm{a}} \exp \left(-c L_{i}\right) \Delta L_{i}$,

where $L_{i}$ is the cumulative leaf area above layer $i, R_{\mathrm{n}, \mathrm{a}}$ the net radiation of the whole canopy and $\Delta L_{i}=l\left(z_{i}\right) \Delta z_{i}$ the leaf area of the corresponding layer, $l\left(z_{i}\right)$ being the leaf area density at height $z_{i}$. Component air and stomatal resistances (amphistomatous case) are expressed as

$r_{\mathrm{a}, i}=\frac{r_{\mathrm{a}, 1}\left(z_{i}\right)}{2 \Delta L_{i}}$ and $r_{\mathrm{s}, i}=\frac{r_{\mathrm{s}, 1}\left(z_{i}\right)}{2 \Delta L_{i}}$,

where $r_{\mathrm{a}, 1}\left(z_{i}\right)$ and $r_{\mathrm{s}, 1}\left(z_{i}\right)$ are respectively the leaf boundary layer resistance and the leaf stomatal resistance (per 
Table 1. Methods used in the numerical simulations to calculate canopy total evaporation with their corresponding equations and their symbol.

\begin{tabular}{lllr}
\hline Method & Equations & Symbol \\
\hline Dry canopy & & \\
\hline General equation without any assumption & Eq. (7) with $R_{\mathrm{c}}$ given by Eq. (8) & $\mathrm{GE}_{\mathrm{d}}$ \\
\hline $\begin{array}{l}\text { Simplified equation: available energy is } \\
\text { equally distributed (soil surface included). }\end{array}$ & $\begin{array}{l}\text { Eq. (13) with resistances given by } \\
\text { Eqs. (20) and (21) }\end{array}$ & $\mathrm{SE}_{\mathrm{d}}$ \\
\hline $\begin{array}{l}\text { Common Penman-Monteith equation with- } \\
\text { out soil surface contribution }\end{array}$ & $\begin{array}{l}\text { Eq. (10) with surface resistance } \\
\text { given by Eq. (9) }\end{array}$ & $\mathrm{PM}_{\mathrm{d}}$ \\
\hline $\begin{array}{l}\text { Partially wet canopy } \\
\text { General equation without any assumption }\end{array}$ & $\begin{array}{l}\text { Eq. (28) with } R_{\mathrm{c}, \mathrm{pw} \text { given by }} \\
\text { Eq. (27) }\end{array}$ & $\mathrm{GE}_{\mathrm{W}}$ \\
\hline $\begin{array}{l}\text { Penman-Monteith-type equation without } \\
\text { soil surface contribution }\end{array}$ & $\begin{array}{l}\text { Eq. (40) with surface resistance } \\
\text { given by Eq. (39) }\end{array}$ & $\mathrm{PM}_{\mathrm{W}}$ \\
\hline
\end{tabular}

unit area of leaf) at each height within the canopy, given by Eqs. (C5) and (C8) respectively. The soil surface resistance $r_{\mathrm{s}, \mathrm{s}}$ has a fixed value depending on soil surface moisture, and the corresponding air resistance $r_{\mathrm{a}, \mathrm{s}}$ (between the soil surface and the canopy source height) is given by Eq. (C7). Calculations are made for an amphistomatous canopy with $z_{\mathrm{h}}=1.2 \mathrm{~m}$ and $L_{\mathrm{t}}=4$ under the following weather conditions at a reference height $z_{\mathrm{r}}=3 \mathrm{~m}$ : incoming solar radiation $R_{\mathrm{s}, \mathrm{a}}=700 \mathrm{~W} \mathrm{~m}^{-2}$, air temperature $T_{\mathrm{a}}=25^{\circ} \mathrm{C}$, vapour pressure deficit $D_{\mathrm{a}}=10 \mathrm{hPa}$, and wind speed $u_{\mathrm{a}}=2 \mathrm{~m} \mathrm{~s}^{-1}$. Two types of leaf area profile are considered, as detailed in Appendix $\mathrm{C}$ and shown in Fig. 2: a profile constant with height (noted A) and another with a high leaf area density in the top layers and a lower density in the bottom layers (B). The canopy is divided into 20 layers plus the soil surface.

\subsection{Numerical results}

The differences among the predictions in relation to different formulations are assessed. In Fig. 3, the generalized combination equation giving canopy evaporation in dry conditions $\left(\mathrm{GE}_{\mathrm{d}}\right)$ is compared with two simplified formulations (see Table 1): $\mathrm{SE}_{\mathrm{d}}$ derived assuming available energy to be equally distributed amongst the exchange surfaces and the common Penman-Monteith equation $\left(\mathrm{PM}_{\mathrm{d}}\right)$. The comparison is made as a function of canopy water stress for two leaf area profiles (A and B). In parallel, the figure shows the variation of canopy surface resistance $r_{\mathrm{s}, \mathrm{c}}$ calculated with methods $\mathrm{SE}_{\mathrm{d}}$ and $\mathrm{PM}_{\mathrm{d}}$. When the soil surface is dry $\left(r_{\mathrm{ss}}=2000 \mathrm{~s} \mathrm{~m}^{-1}\right)$, the simplified equations for canopy evaporation $\left(\mathrm{SE}_{\mathrm{d}}\right.$ and $\mathrm{PM}_{\mathrm{d}}$ ) approximate fairly well the complete formulation: for LAI profile $\mathrm{A}$, the three estimates are practically mingled and the two surface resistances are very close to each other; for profile $\mathrm{B}$, there is a slight underestimation of the simplified formulations $\mathrm{SE}_{\mathrm{d}}$ and $\mathrm{PM}_{\mathrm{d}}$ (Fig. 3a, b). This clearly

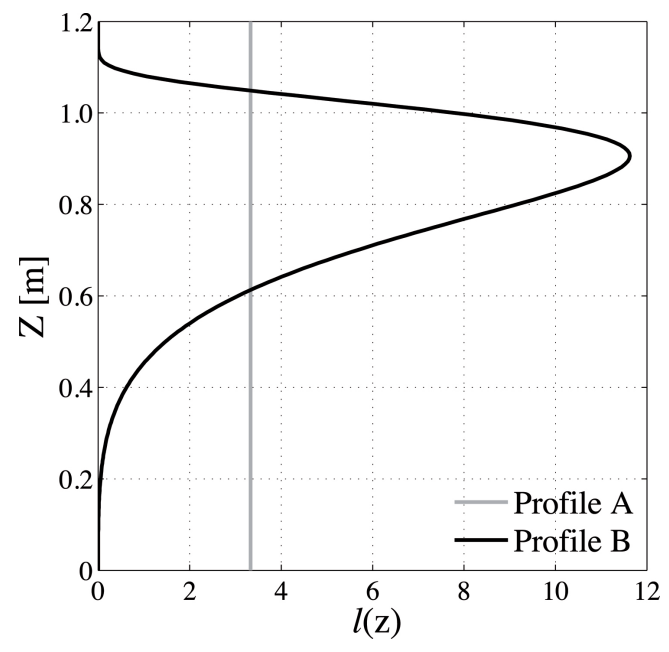

Fig. 2. Profiles of leaf area density considered in the simulation process: (A) constant profile and (B) profile adapted from a gamma function with a higher leaf area density in the top layers.

justifies the use of the Penman-Monteith equation in such conditions. However, when the soil surface becomes wetter $\left(r_{\mathrm{s}, \mathrm{s}}=100 \mathrm{~s} \mathrm{~m}^{-1}\right)$ (Fig. 3c, d), there is a large discrepancy between the formulations: the common Penman-Monteith equation $\left(\mathrm{PM}_{\mathrm{d}}\right)$ clearly underestimates canopy evaporation $\left(\mathrm{GE}_{\mathrm{d}}\right)$, as could be anticipated, and $\mathrm{SE}_{\mathrm{d}}$ tends to overestimate it. In parallel, the surface resistances depart from each other with a departure greater for leaf area profile B.

In Fig. 4, the generalized combination equation established in partially wet conditions $\left(\mathrm{GE}_{\mathrm{w}}\right)$ is compared with its simpler form $\left(\mathrm{PM}_{\mathrm{W}}\right)$ based upon a series of simplifying assumptions. This comparison is made as a function of the fractional surface wetness $W$, assuming the wetting process begins by the top layers, as generally occurs during 

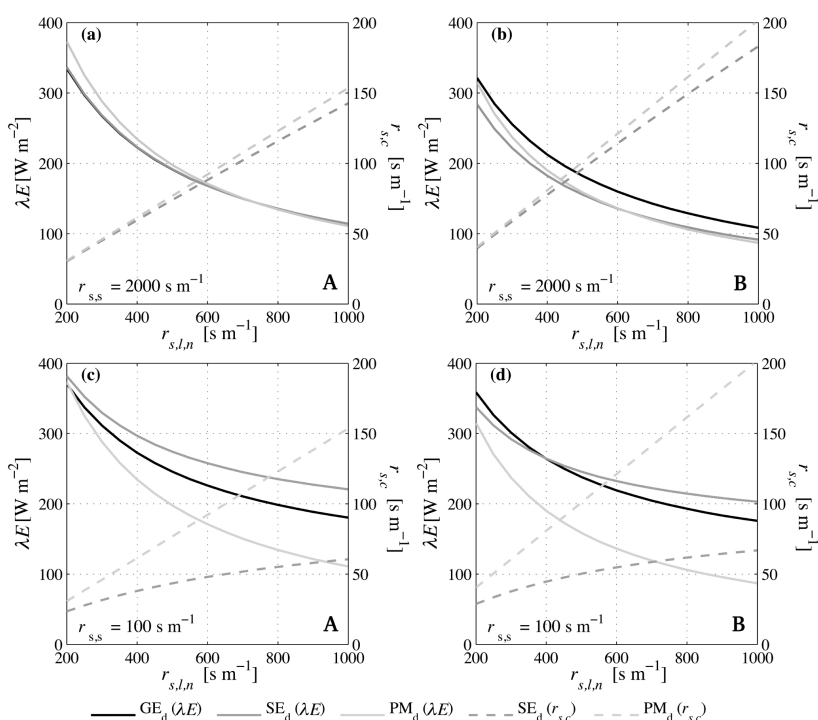

Fig. 3. For a dry canopy, latent heat flux $(\lambda E)$ and canopy surface resistance $\left(r_{\mathrm{s}, \mathrm{c}}\right)$ as a function of minimal stomatal resistance $\left(r_{\mathrm{s}, 1, \mathrm{n}}\right)$ (Eq. C8) representing the canopy water stress. Comparison of three methods $\left(\mathrm{GE}_{\mathrm{d}}, \mathrm{SE}_{\mathrm{d}}, \mathrm{PM}_{\mathrm{d}}\right)$ for two profiles of leaf area density (A and $\mathbf{B})$ and two different values of soil surface resistance: (a) and (b) $r_{\mathrm{s}, \mathrm{s}}=2000 \mathrm{~s} \mathrm{~m}^{-1}$ (dry soil); (c) and (d) $r_{\mathrm{s}, \mathrm{s}}=100 \mathrm{~s} \mathrm{~m}^{-1}$ (moist soil).

rainy events. With leaf area profile A, the Penman-Monteithtype equation $\left(\mathrm{PM}_{\mathrm{w}}\right)$ underestimates the true evaporation rate $\left(\mathrm{GE}_{\mathrm{w}}\right)$ by up to $200 \mathrm{~W} \mathrm{~m}^{-2}$ for a water stressed canopy (Fig. 4c), and the discrepancy decreases when the canopy becomes wetter ( $W$ close to 1 ). With leaf profile $\mathrm{B}$, where most of the leaves are concentrated in the upper half of the canopy, the agreement is better: $\mathrm{PM}_{\mathrm{w}}$ overestimates or underestimates $\mathrm{GE}_{\mathrm{w}}$ depending on surface wetness $(W)$ and canopy water status $\left(r_{\mathrm{s}, 1, \mathrm{n}}\right)$. A reason for this relative agreement could be that leaf profile B is closer to the "big-leaf" model represented by the Penman-Monteith equation. Canopy surface resistance rapidly decreases with the wetting process: when $W=0.5, r_{\mathrm{s}, \mathrm{c}}$ is already close to zero for both profiles.

As previously noticed, the "extra" resistance $\left(r_{\mathrm{a}, \mathrm{c}}\right)$ (Eq. 20), added to the aerodynamic resistance $\left(r_{\mathrm{a}, 0}\right)$ in the Penman-Monteith form of the combination equations (Eqs. 13 and 40), plays the same role as the excess resistance $\left(r_{\mathrm{a}, \mathrm{ex}}=B^{-1} / u *\right)$ introduced by Thom (1972) and mentioned in the introduction. The dimensionless parameter $B^{-1}$ can be estimated by equating $r_{\mathrm{a}, \mathrm{c}}$ to $r_{\mathrm{a}, \mathrm{ex}}: k B^{-1}=\ln \left(z_{0} / z_{0 h}\right)=$ $k u * . r_{\mathrm{a}, \mathrm{c}}$. In Fig. 5a the extra resistance $r_{\mathrm{a}, \mathrm{c}}$ is plotted vs. wind speed at reference height for different LAI using leaf area profile $\mathrm{A} ; r_{\mathrm{a}, \mathrm{c}}$ is also compared with the rough approximation based on $B^{-1}=4$, which is a typical value for permeable vegetation (Thom, 1972). The extra resistance $r_{\mathrm{a}, \mathrm{c}}$ is a decreasing function of wind speed (as could be anticipated) and also of LAI, with values close to the ones predicted by Thom's approximation $\left(r_{\mathrm{a}, \mathrm{ex}}=4 / u *\right)$. In Fig. $5 \mathrm{~b}$,
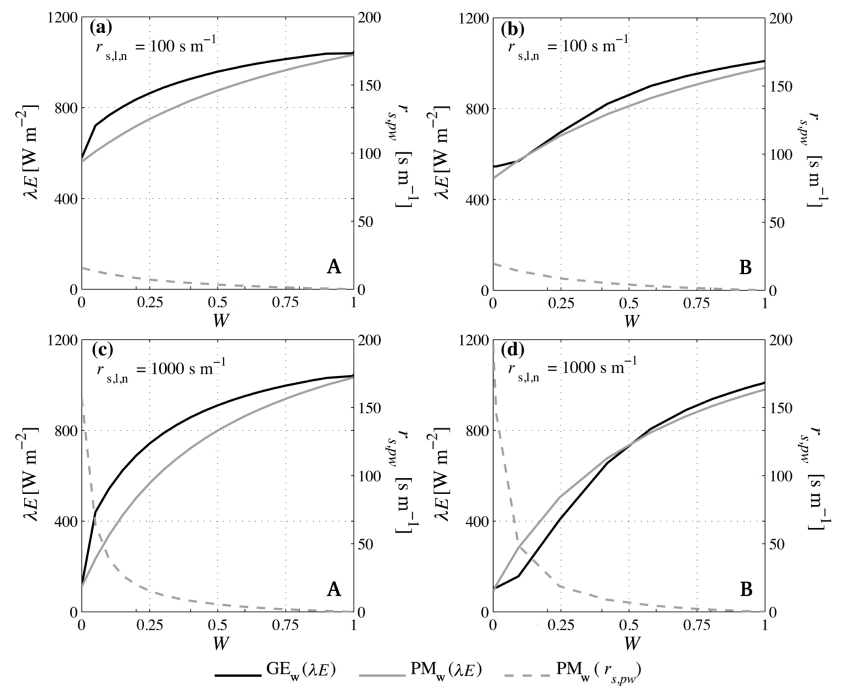

Fig. 4. Latent heat flux $(\lambda E)$ from a partially wet canopy as a function of its fractional surface wetness $(W)$. Comparison of two formulations $\left(\mathrm{GE}_{\mathrm{W}}\right.$ and $\left.\mathrm{PM}_{\mathrm{W}}\right)$ for two profiles of leaf area density (A and $\mathbf{B}$ ) and two different values of minimal stomatal resistance $r_{\mathrm{s}, 1, \mathrm{n}}$ representing canopy water stress: (a) and (b) $r_{\mathrm{s}, 1, \mathrm{n}}=100 \mathrm{~s} \mathrm{~m}^{-1}$ (unstressed canopy); (c) and (d) $r_{\mathrm{s}, 1, \mathrm{n}}=1000 \mathrm{~s} \mathrm{~m}^{-1}$ (stressed canopy). Soil surface resistance $r_{\mathrm{ss}}$ is set to $500 \mathrm{~s} \mathrm{~m}^{-1}$.

$k B^{-1}$ appears as an increasing function of wind speed and a decreasing function of LAI with values ranging approximately from 0.5 to 2 . Compared with the values given by Garrat (1992, Fig. 4.4) for different surface types, our results exhibit a slight underestimation. The same figures drawn using leaf area profile B provide almost identical results (results not shown): this should mean that different leaf area profiles do not lead to substantial change in bulk canopy air resistance. In interpreting these results, it is necessary to keep in mind that (i) the fact of representing canopy elements by layers necessarily restricts the theoretical space; (ii) the model used for simulating the vegetation-atmosphere interaction is itself relatively crude; (iii) the evaluation was done without addressing sensitivity to assumed canopy conditions; (iv) the equation defining $r_{\mathrm{a}, \mathrm{c}}$ (Eq. 20) is a simplified version of a more complex one (Eq. 18); and (v) the $k B^{-1}$ concept itself is questionable and not really physically based (Verhoef et al., 1997).

\section{Conclusions}

The present paper sets a theoretical framework for canopy evaporation through the development of two generalized combination equations - one for completely dry canopies (Eq. 7) and the other for partially wet canopies (Eq. 28) the former being included in the latter. These general equations are derived assuming that all the exchange surfaces are subject to the same vapour pressure deficit at canopy source 

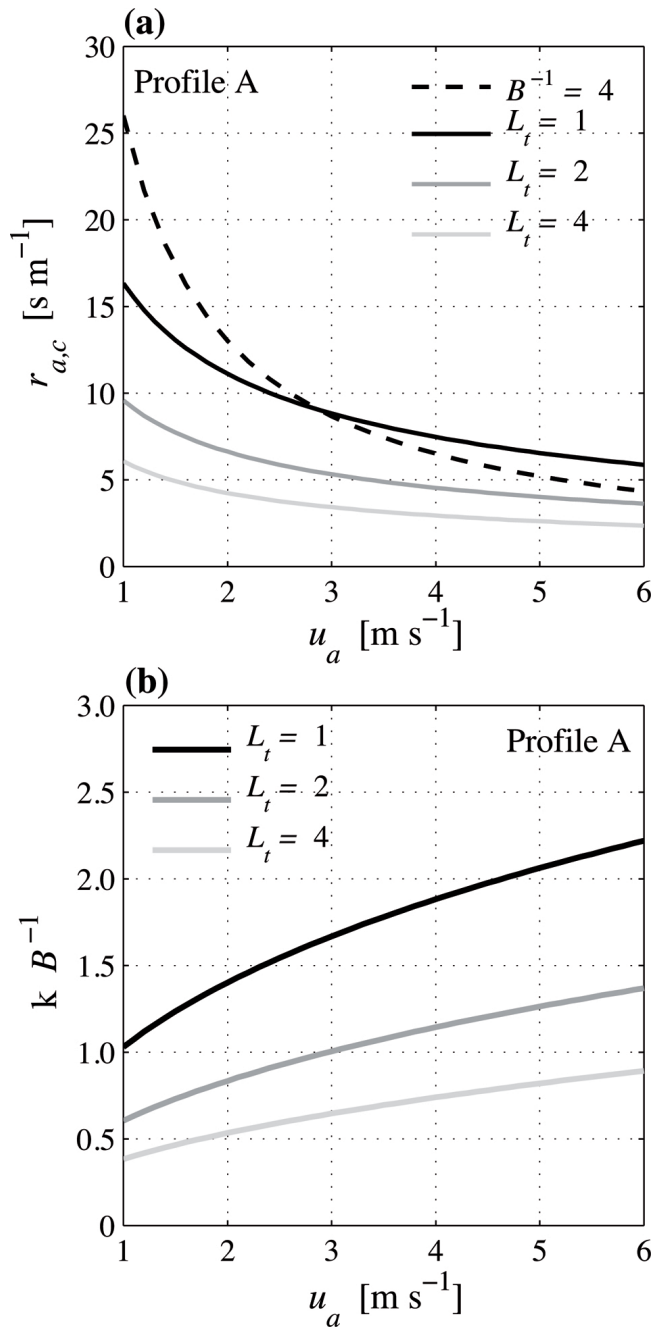

Fig. 5. (a) The additional aerodynamic resistance $\left(r_{\mathrm{a}, \mathrm{c}}\right)$ given by Eq. (20) is plotted as a function of wind speed at reference height $\left(u_{\mathrm{a}}\right)$ for different LAI $\left(L_{\mathrm{t}}\right)$ and compared with the rough estimate based on $B^{-1}=4$ (leaf area profile A); (b) the bulk parameter $k B^{-1}$ (inferred from the value of $r_{\mathrm{a}, \mathrm{c}}$ ) is plotted as a function of wind speed $\left(u_{\mathrm{a}}\right)$ for different LAI $\left(L_{\mathrm{t}}\right)$ and the same profile of LAI.

height. In this sense, as already said, the modelling approach is different from the common multi-layer approach, where the whole canopy is divided into parallel layers, each one subject to a different air saturation deficit, with an additional aerodynamic resistance in relation to the vertical transfer of heat and mass. Comprehensive combination equations have been derived using this approach (Lhomme, 1988a, b), but they are more complex than the equations derived here. Despite their relative simplicity, the present generalized combination equations cannot be easily applied in an operational way, since the available energy partition (within the canopy and between wet and dry surfaces) is required as input. To provide equations easier to handle, assumptions and approximations can be made. In this down-grading process, one of the basic assumptions is to consider that the available energy is equally distributed amongst the exchange surfaces. This hypothesis appears to be rather unrealistic, both in dry and wet conditions, but it leads to simple formulations of the Penman-Monteith type (Eqs. 13 and 40, respectively), which have been successfully used up to now. The numerical simulations, based on a simple one-dimensional model with two types of leaf area profile, confirm that the Penman-Monteith equation performs well in dry conditions, when the soil surface does not evaporate. In partially wet conditions, a discrepancy with the comprehensive formulation exists, but it tends to be less when the leaves are concentrated in the upper part of the canopy.

Acknowledgements. The autors are very grateful to two anonymous reviewers for their useful comments and constructive suggestions.

Edited by: M. Weiler

\section{References}

Choudhury, B. J. and Monteith, J. L.: A four-layer model for the heat budget of homogeneous land surfaces, Q. J. Roy. Meteorol. Soc., 114, 373-398, 1988.

Garrat, J. R.: The Atmospheric Boundary Layer, CUP, Cambridge, UK, 1992.

Garrat, J. R. and Hicks, B. B.: Momentum, heat and water vapour transfer to and from natural and artificial surfaces, Q. J. Roy. Meteorol. Soc., 99, 680-687, 1973.

Inoue, E.: On the turbulent structure of air flow within crop canopies, J. Meteorol. Soc. Japan, 41, 317-326, 1963.

Lhomme, J. P.: Extension of Penman's formulae to multi-layer models, Bound.-Lay. Meteorol., 42, 281-291, 1988a.

Lhomme, J. P.: A generalized combination equation derived from a multi-layer micrometeorological model, Bound.-Lay. Meteorol., 45, 103-115, 1988b.

Lhomme, J. P., Rocheteau, A., Ourcival, J. M., and Rambal, S.: Non-steady state modeling of water transfer in a Mediterranean evergreen canopy, Agr. Forest Meteorol., 108, 67-83, 2001.

Lhomme, J. P., Montes, C., Jacob, F., and Prévot, L.: Evaporation from heterogeneous and sparse canopies: on the formulations related to multi-source representations, Bound.-Lay. Meteorol., 144, 243-262, 2012.

Lhomme, J. P., Montes, C., Jacob, F., and Prévot, L.: Evaporation from multi-component canopies: generalized formulations, J. Hydrol., 486, 315-320, 2013.

Monteith, J. L.: Gas exchange in plant communities, in: Environmental Control of Plant Growth, edited by: Evans, L. T., Academic Press, New York, 95-112, 1963.

Monteith, J. L.: Evaporation and the environment, Symp. Soc. Experiment. Biol., 19, 205-234, 1965.

Monteith, J. L.: Resistance of a partially wet canopy: whose equation fails?, Bound.-Lay. Meteorol., 12, 379-383, 1977.

Penman, H. L.: Natural evaporation from open water, bare soil and grass, Proc. R. Soc. London Ser. A, 193, 120-145, 1948. 
Shuttleworth, W. J.: Experimental evidence for the failure of the Penman-Monteith equation in partially wet conditions, Bound.Lay. Meteorol., 10, 91-94, 1976a.

Shuttleworth, W. J.: A one-dimensional theoretical description of the vegetation-atmosphere interaction, Bound.-Lay. Meteorol., 10, 273-302, 1976b.

Shuttleworth, W. J.: Comments on "Resistance of a partially wet canopy: whose equation fails?", Bound.-Lay. Meteorol., 12, 385386, 1977.

Shuttleworth, W. J.: A simplified one-dimensional theoretical description of the vegetation-atmosphere interaction, Bound.-Lay. Meteorol., 14, 3-27, 1978.

Shuttleworth, W. J.: Putting the "vap" into evaporation, Hydrol. Earth Syst. Sci., 11, 210-244, doi:10.5194/hess-11-210-2007, 2007.
Shuttleworth, W. J. and Wallace, J. S.: Evaporation from sparse crops - an energy combination theorym, Q. J. Roy. Meteorol. Soc.m 111, 839-855, 1985.

Thom, A. S.: Momentum, mass and heat exchange of vegetation, Q. J. Roy. Meteorol. Soc., 98, 124-134, 1972.

Verhoef, A., de Bruin, H. A. R., and van den Hurk, B. J. J. M.: Some practical notes on the parameter $\mathrm{kB}^{-1}$ for sparse vegetation, J. Appl. Meteorol., 36, 560-572, 1997.

Waggoner, P. E. and Reifsnyder, W. E.: Simulation of the temperature, humidity and evaporation profiles in a leaf canopy, J. Appl. Meteorol., 7, 400-409, 1968. 


\section{Appendix A}

Table A1. List of symbols.

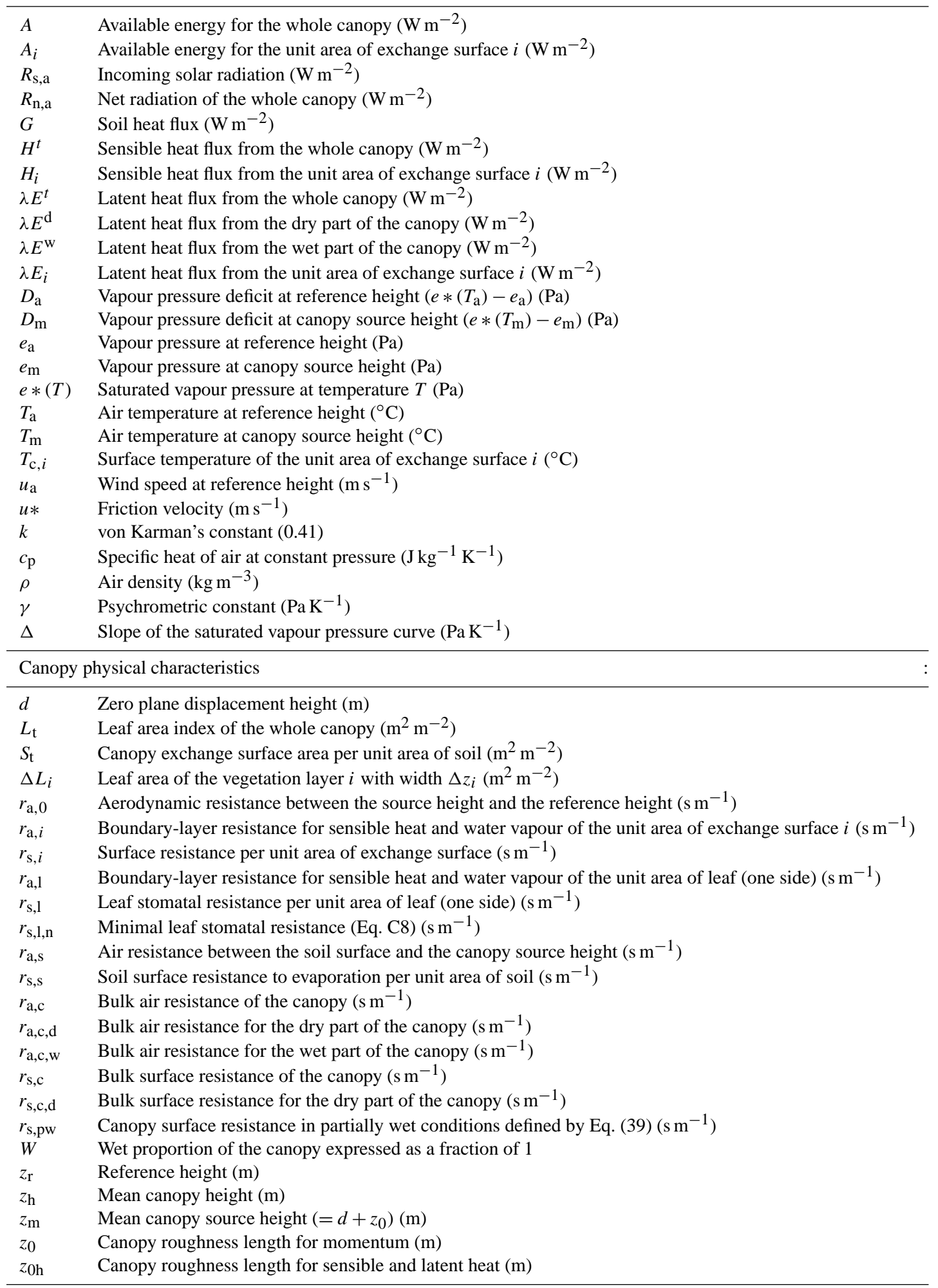




\section{Appendix B}

Expressing the temperature of exchange surfaces $\left(T_{\mathrm{c}, i}\right)$

The basic equations for the transfer of sensible heat are

$H_{i}=\frac{\rho c_{\mathrm{p}}\left(T_{\mathrm{c}, i}-T_{\mathrm{m}}\right)}{r_{\mathrm{a}, i}}$ with $H_{i}=A_{i}-\lambda E_{i}$

$H^{\mathrm{t}}=\frac{\rho c_{\mathrm{p}}\left(T_{\mathrm{m}}-T_{\mathrm{a}}\right)}{r_{\mathrm{a}, 0}}$ with $H^{\mathrm{t}}=A-\lambda E^{\mathrm{t}}$.

Surface temperature is inferred from Eqs. (B1) and (B2):

$$
T_{\mathrm{c}, i}=T_{\mathrm{a}}++\frac{\left(A_{i}-\lambda E_{i}\right) r_{\mathrm{a}, i}}{\rho c_{\mathrm{p}}}+\frac{\left(A-\lambda E^{\mathrm{t}}\right) r_{\mathrm{a}, 0}}{\rho c_{\mathrm{p}}} .
$$

Elementary flux $\lambda E_{i}$ is given by Eq. (3) with $D_{\mathrm{m}}$ expressed by Eq. (5). Substituting and rearranging gives the following expression of $T_{\mathrm{c}, i}$ as a function of $\lambda E^{\mathrm{t}}$ (Eq. 7):

$$
\begin{aligned}
T_{\mathrm{c}, i}-T_{\mathrm{a}} & =\frac{1}{\rho c_{\mathrm{p}}}\left\{\left[\left(A-\lambda E^{\mathrm{t}}\right) r_{\mathrm{a}, 0}+A_{i} r_{\mathrm{a}, i}\right]\left(1-\frac{\Delta}{\gamma} \frac{r_{\mathrm{a}, i}}{R_{i}}\right)\right\} \\
+ & \frac{r_{\mathrm{a}, i}}{R_{i}}\left(\frac{\lambda E^{\mathrm{t}} r_{\mathrm{a}, 0}}{\rho c_{\mathrm{p}}}-\frac{D_{\mathrm{a}}}{\gamma}\right) .
\end{aligned}
$$




\section{Appendix C}

\section{Parameterizations used in the simulation process}

Solar radiation $R_{\mathrm{S}}$ and net radiation $R_{\mathrm{n}}$ are assumed to decrease within the canopy as exponential functions of the cumulative leaf area index $L(z)$ (Beer's law) counted from the top of the canopy

$R_{\mathrm{S}}(z)=R_{\mathrm{S}, \mathrm{a}} \exp [-c L(z)]$,

$R_{\mathrm{n}}(z)=R_{\mathrm{n}, \mathrm{a}} \exp [-c L(z)]$.

The attenuation coefficient is assumed to be the same for both profiles: $c=0.60$. Net radiation above the canopy $R_{\mathrm{n}, \mathrm{a}}$ is calculated as $60 \%$ of global radiation $R_{\mathrm{s}, \mathrm{a}}$ and soil heat flux $G$, as half the net radiation reaching the soil surface. The profile of wind speed within the canopy is given by

$u(z)=u\left(z_{\mathrm{h}}\right) \exp [-\beta L(z)]$,

where $u\left(z_{\mathrm{h}}\right)$ is the wind speed at canopy height $z_{\mathrm{h}}$ (inferred from wind speed $u_{\mathrm{a}}$ at reference height $z_{\mathrm{r}}$ using a simple logarithmic profile) and $\beta=0.5$ (Inoue, 1963). Two profiles of leaf area density $l(z)$ are considered: one is constant with height $l(z)=L_{\mathrm{t}} / z_{\mathrm{h}}$ (profile A) and the other (profile B) uses a gamma-type function to represent a canopy with a higher leaf area density in the top layers, as frequently occurs,

$l(z)=\Lambda_{0} u^{\gamma-1} \exp (-u)$ with $u=\frac{z_{\mathrm{h}}}{z}-1$.

The shape parameter $\gamma$ is taken equal to 4 and $\Lambda_{0}$ is determined as $L_{\mathrm{t}} / \int_{0}^{z_{\mathrm{h}}} l(z) \mathrm{d} z$ to obtain a canopy LAI equal to $L_{\mathrm{t}}$. Leaf boundary-layer resistance (per unit one-sided leaf area) is calculated as a function of wind speed and leaf width $w$ (0.01 m) as (Choudhury and Monteith, 1988) $r_{\mathrm{a}, 1}(z)=\alpha[w / u(z)]^{1 / 2}$,

with $\alpha=200$ in SI units. For the sake of convenience, the aerodynamic resistance above the canopy is expressed as a simple function of wind speed without stability correction:

$r_{\mathrm{a}, 0}=\frac{1}{k u^{*}} \ln \left[\frac{z_{\mathrm{r}}-d}{z_{0}}\right]$,

where $u *=k u_{\mathrm{a}} / \ln \left[\left(z_{\mathrm{r}}-d\right) / z_{0}\right]$ with $d=0.63 z_{\mathrm{h}}$ and $z_{0}=$ $0.13 z_{\mathrm{h}}$. The air resistance between the soil surface and the canopy source height is given by Choudhury and Monteith (1988):

$$
\begin{aligned}
r_{\mathrm{a}, \mathrm{s}} & =\frac{z_{\mathrm{h}} \exp (\omega)}{\omega K\left(z_{\mathrm{h}}\right)}\left\{\exp \left[-\omega z_{0, \mathrm{~s}} / z_{\mathrm{h}}\right]\right. \\
& \left.-\exp \left[-\omega\left(d+z_{0}\right) / z_{\mathrm{h}}\right]\right\},
\end{aligned}
$$

where $K\left(z_{\mathrm{h}}\right)=k^{2} u_{\mathrm{a}}\left(z_{\mathrm{h}}-d\right) / \ln \left[\left(z_{\mathrm{r}}-d\right) / z_{0}\right]$ is the value of eddy diffusivity at canopy height, $\omega=2.5$ (dimensionless) and $z_{0, \mathrm{~s}}=0.01 \mathrm{~m}$. The profile of leaf stomatal resistance (per unit one-sided leaf area) is made a function of solar radiation within the canopy following a Jarvis-type formulation:

$r_{\mathrm{s}, 1}(z)=\frac{r_{\mathrm{s}, 1, \mathrm{n}}}{1-\exp \left[-v R_{\mathrm{s}}(z)\right]}$,

where $r_{\mathrm{s}, 1, \mathrm{n}}$ is a minimal stomatal resistance, which depends on available soil water, and $v=0.009$ with $R_{\mathrm{S}}$ expressed in $\mathrm{W} \mathrm{m}^{-2}$ (Lhomme et al., 2001). 